\title{
Landscape, vegetation characteristics, and group identity in an urban and suburban watershed: why the 60s matter
}

\author{
Christopher G. Boone • Mary L. Cadenasso • \\ J. Morgan Grove • Kirsten Schwarz • \\ Geoffrey L. Buckley
}

Published online: 20 November 2009

(C) The Author(s) 2009. This article is published with open access at Springerlink.com

\begin{abstract}
As highly managed ecosystems, urban areas should reflect the social characteristics of their managers, who are primarily residents. Since landscape features develop over time, we hypothesize that present-day vegetation should also reflect social characteristics of past residents. Using an urban-to-suburban watershed in the Baltimore Metropolitan Region, this paper examines the relationship between demographics, housing characteristics, and lifestyle clusters from 1960 and 2000 with areas of high woody and herbaceous vegetation cover in 1999. We find that 1960 demographics and age of housing are better predictors of high woody or tree coverage in 1999 than demographics and housing characteristics from 2000. Key variables from 1960 are percent in professional occupations $(+)$, percent of pre-WWI housing $(-)$, percent of post-WWII housing $(+)$, and population density ( - ). Past and present demographic and housing variables are poor predictors of high herbaceous cover in 1999. Lifestyle clusters for 2000 are very good predictors of high herbaceous coverage in 1999, but lifestyle clusters from 1960 and 2000 are poor predictors of high woody vegetation coverage. These findings suggest that herbaceous or grassy areas, typically lawns, are good reflections of contemporary lifestyle characteristics of residents while neighborhoods with heavy tree canopies have largely inherited the preferred landscapes of past residents and communities. Biological growth time scales of trees and
\end{abstract}

C. G. Boone $(\bowtie)$

School of Human Evolution \& Social Change, School of Sustainability, Arizona State University, P.O. Box 875502, Tempe, AZ 85287-5502, USA

e-mail: cgboone@asu.edu

M. L. Cadenasso

Department of Plant Sciences, University of California-Davis, Davis, CA, USA

J. M. Grove

Northern Research Station, USDA Forest Service, Baltimore, MD, USA

K. Schwarz

Ecology and Evolution, Rutgers University, New Brunswick, NJ, USA

G. L. Buckley

Department of Geography, Ohio University, Athens, OH, USA 
woody vegetation means that such vegetation may outlast the original inhabitants who designed, purchased, and planted them. The landscapes we see today are therefore legacies of past consumption patterns.

Keywords Urban landscapes $\cdot$ Social predictors $\cdot$ Legacies $\cdot$ Baltimore

\section{Introduction}

Urban ecosystems are highly managed in order to meet primarily the needs and wishes of people (Dow 2000; Grimm et al. 2008). As such, the vegetation landcover in cities typically reflects, in addition to the biophysical potential and limitations of the site, the culture and values of people and decision makers who plant and care for trees, shrubs, gardens, and grass (Spirn 1984; Burgi et al. 2004). Vegetation in cities can serve fundamental purposes of providing food (fruits and vegetables), shade, or play and recreation areas. Economists have also demonstrated that lush and well maintained trees and yards can add value to homes (Luttik 2000; Mansfield et al. 2005).

Landscaping and gardening can help build connections with "nature," serve as hobbies, and satisfy a yearning for beauty. They can also convey status or serve as external markers of who lives inside the dwelling beyond the front yard. Some research, described below, also shows that landscaping reflects more than individual character. Even on private property, the choice of landscaping may mirror the vegetation patterns of surrounding properties and the neighborhood as a whole. Pressure to conform and the status associated with a well-kept yard, which Troy et al. (2007) term an "ecology of prestige," can result in neighborhoods swathed in similar green lawns and trees. Landscaping firms also fuel the desire to keep up with the neighbors (Robbins 2007). Even when residents who call themselves environmentalists and understand the negative ecological consequences of fertilizing lawns, the pressure is great enough that they will do so regardless.

Urban landscapes typically have very little productive value in terms of economic returns to consumers; rather they are more often forms of consumption. Similar to other types of consumption, landscapes should reflect the status and characteristics of the consumer at both the individual or household level as well as the neighborhood. However, landscapes, especially woody vegetation, are not instant - they depend on biological growth time scales that may outlast the original inhabitants who designed, purchased, and planted them. The landscapes we see today are therefore legacies of past consumption patterns. This paper addresses the question of whether socio-demographic and housing characteristics of the past are significant predictors of urban landcover of the present, using the Gwynns Falls Watershed in Metropolitan Baltimore as a case study.

Social predictors of urban landscapes

Urban landscapes are heterogeneous, a patchwork of built and vegetation land covers, multiple land uses, and social groupings. Because urban landscapes are highly managed, it follows that the patchwork of cities should reflect the characteristics, preferences, resources, efforts, and influences of their managers, including homeowners. Existing research shows that the distribution of trees and grassy lawns in cities are, like most urban characteristics, uneven, and that those patterns are related to social characteristics of neighborhoods.

As one would expect, scarcity of tree and grass cover is typically a function of population density. As population densities increase, vegetation cover tends to decline as 
built-residential uses out-compete non-built land uses (Nowak et al. 1996; Iverson and Cook 2000). However, population density alone cannot explain the variation in vegetation cover in cities. Suburbs usually contain more green cover than downtown cores, but within urban areas, the leafiest and greenest areas are often also the wealthiest (Talarchek 1990; Martin et al. 2004; Jensen et al. 2004; Mennis 2006). This association between wealth and vegetation has been observed for cities in the United States and elsewhere (Escobedo et al. 2006; Kirkpatrick et al. 2007; Conway and Hackworth 2007). These findings suggest that greater wealth provides residents and neighborhoods with more resources to plant and take care of vegetation, and the greenness of wealthy communities may be self-reinforcing, as it attracts more wealthy residents. Trees and green spaces also increase property values, which increases tax bases for planning and maintenance of public spaces, and may attract further high-income buyers to the neighborhood.

Although income is an important predictor of vegetation, other social characteristics such as education and ethnicity are strongly associated with greenspace in cities. A study of urban forest canopy cover in 60 cities in central Indiana, for instance, found that tree cover was significantly and positively correlated with percent of persons holding a college degree (Heynen and Lindsey 2003). Landscapes also reflect dominant cultures. In a study of vegetation characteristics and ethnicity in Toronto, homeowners of British heritage were more likely to have shade trees on their properties than persons of Chinese ancestry (Fraser and Kenney 2000).

Others have pointed to lifestyles, typologies of neighborhoods or individuals based on a combination of socioeconomic and housing characteristics, as key determinants of vegetation. In a study of vegetation on private property parcels in Baltimore, Troy et al. (2007) found that lifestyle categories were strongly correlated with what they term realized stewardship, or the percent of potential pervious surface on properties that is vegetated. Specifically they found that a well-educated but less wealthy lifestyle category has $52 \%$ less realized stewardship than the well-educated and higher income lifestyle group. Even though the population densities are similar, the first lifestyle group tends to be younger and more likely to live in rental or multi-unit housing than the second lifestyle group. Other studies have found that renters live in areas with lower urban tree canopy cover than homeowners (Emmanuel 1997; Perkins et al. 2004). Renter is a social class and a housing characteristic, both of which tend to result in less commitment to long term property maintenance, shortterm or temporary timelines for residents, and relatively weak political power to demand city services, such as street trees.

Vegetation characteristics of properties are also the result of a neighborhood effect. Property owners often mimic the landscaping practices and preferences of their neighbors (Zmyslony and Gagnon 2000). Grove et al. (2006) describe this phenomenon of mimicry as an ecology of prestige, the phenomenon in which household patterns of consumption and expenditure on environmentally relevant goods and services are motivated by group identity and perceptions of social status associated with different lifestyles (Grove et al. 2005; Law et al. 2004). This theory suggests that a household's land management decisions are influenced by the desire to uphold the prestige of its community and outwardly express its membership in a given lifestyle group. Conceptions of luxury and prestige, however, are highly variable, even within the same income or demographic group. Lifestyle variables may only be weakly correlated with socioeconomic status, such as family size, marriage status, and life stage. However, lifestyle can play a critical role in determining where households choose to locate and how they manage their properties (Timms 1971; Knox 1994; Short 1996; Gottdiener and Hutchinson 2000; Kaplan et al. 2004). 
Legacy effects on urban landscapes

In newly-built suburbs, the vegetation cover may be an expression of the current social and housing characteristics of the resident or neighborhood, although it is more likely the perception of what the developer believes will satisfy buyers. Newly-built neighborhoods are also more likely to have new vegetation, such as small saplings, especially if the land was formerly agricultural or the developer clears forests for construction. In long established neighborhoods, where residents have come and gone, existing vegetation may reflect the tastes and wishes of past residents. People moving into older homes thus inherit past social preferences of landscapes. Even in newly-built suburbs, legacies from past land uses, such as woodlands or agricultural fields, may put their stamp on current landscapes (Dow 2000). A central question of this research is whether past social and housing characteristics are better predictors of woody and herbaceous vegetation than current social and housing characteristics. Some prior research, though limited, suggests that past inhabitants and age of housing are significant predictors of current vegetation in urban areas (Heynen and Lindsey 2003; Martin et al. 2004). In a pioneering study, Grove (1996) found that 1970 social characteristics were the best predictors of 1990 vegetation in the Gwynns Falls Watershed of Baltimore. Using a parcel-level analysis, age of housing was also found to be an important predictor of vegetation abundance in Baltimore City (Grove et al. 2006; Troy et al. 2007). Amount of realized stewardship, or percent cover of potentially vegetated surface per parcel, shows an inverted-U relationship with age of housing, peaking in 1950 (Troy et al. 2007). This article builds on Grove's (1996) analysis of the Gwynns Falls Watershed by using an updated and high resolution land cover layer of vegetation, census data from 2000, and by examining, in addition to demographics and housing, the association between lifestyle and vegetation cover. Group identity, we argue, is a powerful force in defining neighborhood characteristics, including its vegetation.

\section{Group identity}

Group identity can be expressed in a number of material ways, from gang colors, to uniforms, to flags. It can also be manifest in the landscape, as generations of social scientists have shown (Sauer 1925; Cosgrove 1998). The study of the cultural landscape is well established, albeit with a bias toward the rural rather than urban. A trained scholar can pick out remnants of past cultures, even from very fragmentary evidence; the shape of a barn, the construction of a fence, or shards of pottery are used to identify folkways that bind together individuals into groups through a common way of doing something (Anderson 2001). When studying the urban environment, making the linkage between the legacies of culture, or group identity, and landscape can tell us more about the dynamics of urban ecology compared to purely contemporary associations (Dow 2000; Cadenasso et al. 2006). In this paper we argue that group dynamics are key to understanding behavior that impacts landscape management at the neighborhood level.

Identifying what constitutes a group is a difficult endeavor, something that has kept legions of social scientists busy for decades (Côté and Levine 2002). Single variables like race, income, or education can go a long way in teasing apart the elements of group identity, but given their colinearity, a number of methods have been derived to search for the bundle of variables that tell us what makes groups different and separate from one another. Part of group identity is defined by where people live (Weiss 2000). Similar individuals or households cluster geographically. These clusters may be self-reinforcing by attracting similar people to certain neighborhoods, strengthening a sense of neighborhood 
or group identity, and at the same time shunning those that do not share that group's identity (Massey and Denton 1993). Cities are, however, dynamic places and such patterns can shift over time. Every reader can think of a neighborhood that has changed in social characteristics, sometimes slowly and sometimes surprisingly quickly. On the other hand, many neighborhoods and the characteristics of people who inhabit them can remain remarkably stable. In neighborhoods there is a high amount of fixed, social, and even emotional capital, sometimes referred to as attachment to place. Such investments will be carefully guarded and defended, in extreme cases through violence and intimidation. In subtler ways neighborhoods retain their identity because the sense of group membership is so strong that few outsiders feel welcome. As disagreeable as clustering (or put another way, segregation) may seem to some, it is a powerful force that shapes patterns and processes of urban landscapes.

\section{Methods}

\section{Lifestyle clusters}

Marketers are wise to the linkages between consumption patterns and group identity as expressed through shared traits, including location. They have found that targeted marketing for many products is more efficient and effective than a shotgun approach. Given the very real value of this information, companies have seized on the opportunity to provide such information to vendors. In 1976, the Claritas Corporation (now owned by the Nielson Company) developed the PRIZM* (Potential Rating Index for Zip Codes) market segmentations and sells this product as a marketing tool. The segmentation uses factor and cluster analyses of census data, and releases its results using census geographic units - the census block group, census tract - and at the zip code level. Point of purchase data is then matched to the lifetsyle clusters, so that the company can tell vendors what types of products are likely to sell well in particular zip codes or census tracts. For this study, we use PRIZM lifestyle classifications at the census tract level for 2000 and generate pseudoPRIZM lifestyle clusters for 1960, described below. These data are overlaid onto a vegetation layer derived from 1999 orthoimagery.

\section{Land cover classification}

To overcome limitations of using the Anderson land classification system in urban areas, we use a new classification developed by Cadenasso et al. (2007) that describes biophysical heterogeneity of urban landscapes at fine scales. This classification is called HERCULES (High Ecological Resolution Classification for Urban Landscapes and Environmental Systems) and is built using a logic of land cover. HERCULES describes variation in three urban physical elements - buildings, vegetation, and surfaces (Ridd 1995). Within these three elements, variation in the building type and cover, vegetation type and cover, and type and cover of surfaces, determines a patch boundary and classification.

To create a HERCULES patch layer, high resolution digital aerial imagery was used. The imagery was collected for the Gwynns Falls watershed in October 1999. It is three band color infrared, with green $(510-600 \mathrm{~nm})$, red $(600-700 \mathrm{~nm})$, and near infrared $(800$ $900 \mathrm{~nm}$ ) bands. Pixel size for the imagery is $0.6 \mathrm{~m}$. Land cover patches, using the HERCULES system, were digitized and the proportion cover of each component estimated via visual interpretation. The patch layer can be queried for variation in any one feature or 
combination of two or more features. In the analysis presented here, patches that contained greater than $75 \%$ cover of woody vegetation or fine vegetation were used (Fig. 1). We chose only these categories in order to examine associations between population and housing characteristics and patches with a high percentage of woody (coarse) vegetation and a high percentage of herbaceous (fine) vegetation cover.

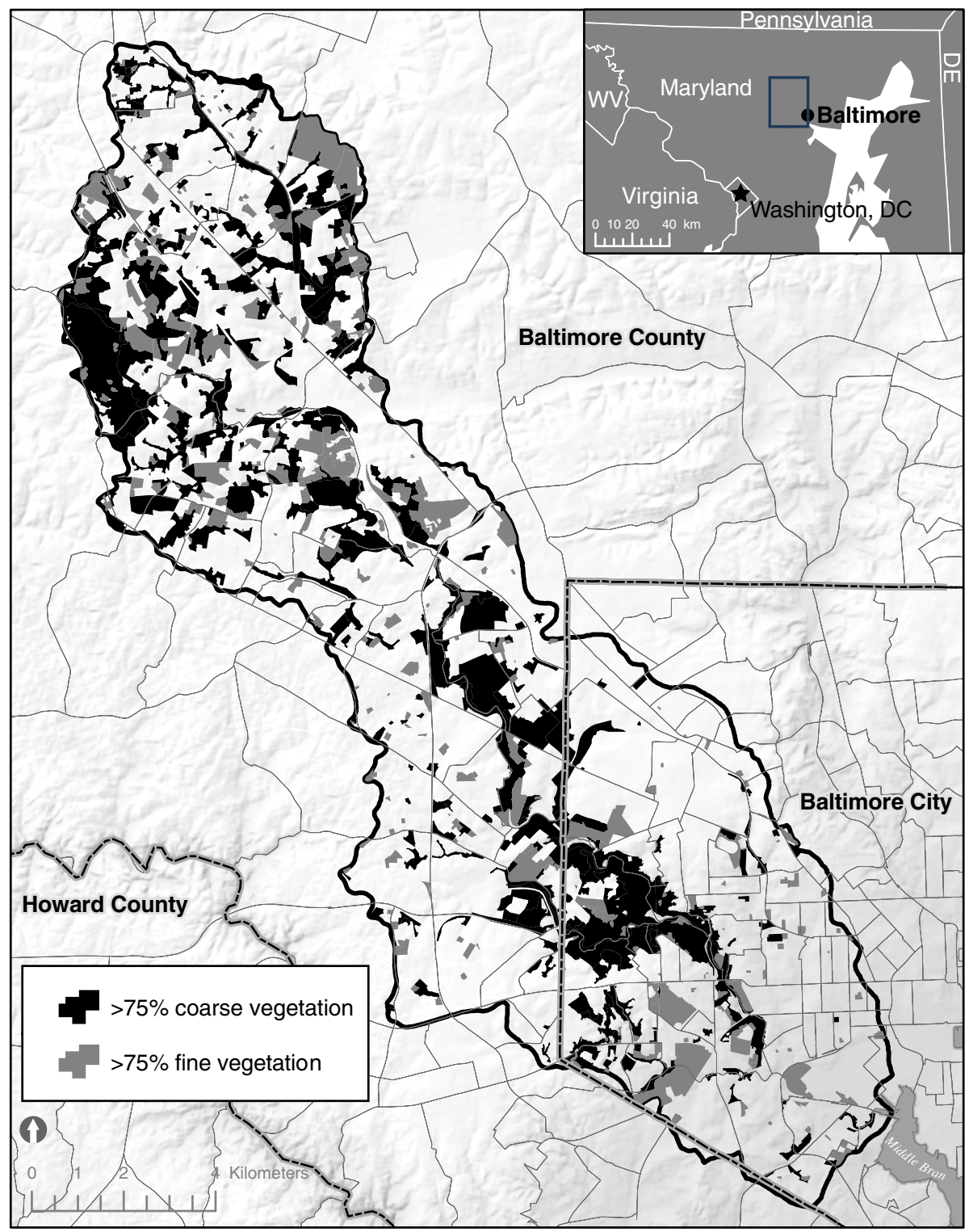

Fig. 1 Patches that contain greater than $75 \%$ coverage of coarse woody vegetation and fine herbaceous vegetation according to HERCULES classification for the Gwynns Falls watershed, 1999 
Lifestyle clusters, 1960

PRIZM lifestyle clusters are not available for 1960, so we began by generating pseudoPRIZM classifications using 1960 population and housing characteristics. We used SPSS to run a factor analysis (principal components analysis) on selected population and housing characteristics, using a varimax rotation. Twelve factors returned an eigen value greater than 1. Based on the slope of the scree plot and the eigen values, we chose the first nine factors to create the neighborhood typology (Table 1).

To map the above typologies by census tract, we worked in order of factors so that higher eigen value factors would trump lower value eigen value factors in designating the typology of each census tract. Each factor was separated into three classes: VV for "Very Very" if the factor score was greater than 2.5 standard deviations, V for "Very" if the factor score fell with a standard deviation between 1 and 2.5, and no prefix if standard deviation was between .5 and 1 . This system borrows from a similar study of Chicago neighborhoods (http://www.lib.uchicago.edu/e/su/maps/neighborhoodnote.html). Using this method all categories except the Farm Country typology define a neighborhood in the Gwynns Falls Watershed. This demonstrates that the Gwynns Falls watershed offers a useful "gradient" or "patchwork" of neighborhood types, since nearly all neighborhood types are found here (see Appendix I for factor loadings).

We used two approaches to analyze the relationship between social characteristics and coarse and fine vegetation cover. In the first, we created linear regression models of standard demographic variables (population density, median family income, percent white, percent of houses owner-occupied, and median year built for houses) and percent area of high coarse and fine vegetation cover by census tract. For the lifestyle clusters calculated

Table 1 Neighborhood typologies based on PCA of population and housing characteristics, 1960. Names mirror those used by Claritas in the PRIZM classification. Factor loadings are available from the corresponding author

\begin{tabular}{|c|c|c|c|}
\hline $\begin{array}{l}\text { Neighborhood } \\
\text { typology }\end{array}$ & $\begin{array}{l}\text { Eigen } \\
\text { value }\end{array}$ & $\begin{array}{l}\% \text { of } \\
\text { variance }\end{array}$ & Description \\
\hline Blue Blood & 6.168 & 12.436 & $\begin{array}{l}\text { High income census tracts with high value homes. Persons are } \\
\text { employed in the professional and managerial classes and have college } \\
\text { degrees. }\end{array}$ \\
\hline $\begin{array}{l}\text { Inner-city } \\
\text { Minority }\end{array}$ & 6.086 & 11.270 & $\begin{array}{l}\text { Low income, nonwhite, young population living in high densities. } \\
\text { Persons are employed in the laborer and household services } \\
\text { occupations. }\end{array}$ \\
\hline $\begin{array}{l}\text { High-school } \\
\text { Achievers }\end{array}$ & 5.881 & 10.891 & $\begin{array}{l}\text { High School educated population living in newer, low-density housing } \\
\text { and with moderate incomes. }\end{array}$ \\
\hline $\begin{array}{l}\text { Post-War } \\
\text { Dreams }\end{array}$ & 5.599 & 10.368 & $\begin{array}{l}\text { White, middle-income people who own single, detached dwellings. } \\
\text { Craftsmen and foremen are the dominant occupation. }\end{array}$ \\
\hline $\begin{array}{l}\text { Everything } \\
\text { New }\end{array}$ & 4.268 & 7.903 & $\begin{array}{l}\text { Young families with children who have recently moved into new } \\
\text { houses. }\end{array}$ \\
\hline $\begin{array}{l}\text { Property } \\
\text { Values }\end{array}$ & 3.406 & 6.308 & Areas of higher-valued properties. \\
\hline Euro Ghettos & 2.647 & 4.902 & $\begin{array}{l}\text { High percentage of white, foreign persons and of foreign parentage. } \\
\text { Dominant occupations in sales. }\end{array}$ \\
\hline Empty Nesters & 2.266 & 4.197 & Older, married couples living in older houses. \\
\hline Farm Country & 2.210 & 4.092 & Dominated by farmers and farm laborers. \\
\hline
\end{tabular}

Factor loadings are included in the Appendix 
for 1960 and the PRIZM classes for 2000, since they are categorical, we created dummy variables and regressed them against the percent coverage of census tracts for high and low coarse vegetation and for high fine vegetation (for 1999).

\section{Results}

Legacy effects: Population and housing characteristics

The first set of analyses test the relationships between population and housing characteristics and coarse vegetation cover. We find that past social and housing characteristics are better than present social and housing characteristics for predicting current coarse vegetation cover in the Gwynns Falls Watershed. Using the 1960 census tract data, bivariate analyses show a positive and significant relationship between percent of area with high coarse vegetation cover from 1999 and (i) percent in professional occupations; and (ii) percent houses built between 1950 and 60. The relationship is negative and significant for (iii) percent houses built before 1940; (iv) population density; and (v) percent nonwhite. Using 2000 census data, only median family income $(+)$ and population density $(-)$ are significantly correlated with percent coverage of high coarse vegetation (Table 2).

Using linear regression, we find that the best model for predicting the percent coverage of high coarse vegetation in 1999 are variables from the 1960 census, including percent in professional occupations $(+)$ and percent of houses built before $1940(-)$. This model has an adjusted $R^{2}$ of .342 , with a standardized beta coefficient of .306 (sig. .018) for percent professional, and -.347 (.008 significance) for percent of housing built before 1940. The best model using 2000 census data returned an adjusted $R^{2}$ of .222 , with a standardized beta coefficient of -.405 (sig. .000) for population density, and .112 (.045 significance) for median family income.

Troy et al. (2007) have shown an inverted-U relationship between age of housing and "realized stewardship" at the parcel level. Simply put, the amount of coarse canopy cover is low on properties of older houses, highest for houses built around 1950, and lower for newer houses. For newer homes, this in part may be a function of growing periods of trees, but may also be a function of changing lifestyle choices, from one of small houses on large lots to large houses on smaller lots. Older neighborhoods, built before the widespread use of the automobile, also tend to have higher densities, reducing the opportunities for extensive tree canopies. In Baltimore, this is typified by the iconic row houses that face directly on

Table 2 Correlation coefficients (Spearman's rho) for 1960 and 2000 census data and percent of high coarse vegetation cover in 1999 by census tract

Independent variables

\% professional occupations (1960)
$\%$ houses built 1950-60 (1960)
$\%$ houses built before 1940 (1960)
Population density (1960)
$\%$ nonwhite (1960)
Median family income (2000)
Population density (2000)
\% CT coverage of high coarse vegetation class (1999)

**significant at the $p<.0001$ level 
the street with little or no setback from the sidewalk. Planting trees under these conditions is difficult and costly, and increases morbidity and mortality rates of trees (Nowak et al. 2004). Street tree planting can be more than a technical challenge; in some neighborhoods trees are seen as a nuisance (Buckley 2010).

We find in this study that the age of housing 40 years ago continues to affect coarse vegetation cover today. In census tracts that had a greater percentage of newer housing (built between 1950 and 1960), the percentage of present-day coarse vegetation cover tends to be larger than for census tracts that had older housing (built before 1940). This could be a factor of tree death and households not replanting, or it could be that trees were not planted to the same degree in older neighborhoods as in newer communities.

In the Gwynns Falls Watershed, fine herbaceous cover shows a large degree of variability across census tracts, ranging from almost no coverage to a high of $44 \%$ (mean of $6.3 \%$ and standard deviation of $8 \%$ ). However, demographics and housing characteristics from 1960 are a poor predictor of current patches of high herbaceous cover. None of the population or housing variables from 1960 is significantly correlated with present-day grassy patches.

However, demographics and housing characteristics from the year 2000 do show significant relationships with herbaceous cover. Race variables are significantly but weakly associated with high herbaceous cover, negatively for percent white and positively with percent black. Median household and median family income as well as percent homeowners are negatively correlated with percent of high herbaceous cover, while percent of renters is positively correlated. Newer housing is negatively and significantly related with high herbaceous cover while older housing shows a significant and positive correlation. Given the negative relationship between income and herbaceous cover, census tracts with a more educated public follows expected trends with a negative and significant correlation with high herbaceous cover. Population density is not significantly correlated with high herbaceous cover (Table 3). None of the regression models offer reasonable predictive power (all had an adjusted r-square of less than 0.1).

Legacy effects: Lifestyle clusters

The second set of analyses tests the relationship between lifestyle clusters and vegetation. We find that the 1960 lifestyle clusters are not very good predictors of high coarse vegetation patches $(>75 \%$ cover) in 1999 . When we regressed percent coverage of high

Table 3 Correlation coefficients (Spearman's rho) for 2000 census data and percent of high herbaceous vegetation cover by census tract. None of the 1960 census variables was significantly correlated with high herbaceous cover

\begin{tabular}{ll}
\hline Independent variables & $\%$ CT coverage of high herbaceous vegetation class (1999) \\
\hline Median household income & $-225^{* *}$ \\
$\%$ houses built $1990-2000$ & $-.221^{* *}$ \\
$\%$ house built before 1940 & $.164^{* *}$ \\
$\%$ of adults with a bachelor's degree & $-.193^{* *}$ \\
$\%$ of adults with some high school & $.225^{* *}$ \\
$\%$ black & $.103^{*}$ \\
Median household income & $.138^{* *}$
\end{tabular}

$* *$ significant at the $p<.0001$ level 
coarse vegetation against dummy variables for neighborhood typology, the model returned an adjusted $R^{2}$ of only .057 . Descriptive statistics show that, of the neighborhoods that contain high coarse vegetation patches, Post-War Dreams had the highest mean value (15.9\%) of coverage, followed by the Very High School Achievers (14.1\%) and High School Achiever (13.5\%) neighborhoods. The lifestyle clusters were better, however, at predicting the lack of coarse vegetation patches. The model returned an adjusted $R^{2}$ of .234 (sig. .000). But only two (Property Values and Very Inner-City Minority) of the twelve dummy variables were significant. The descriptive statistics show that High School Achievers (28.3\%) and Very High School Achievers (19.6\%) had the highest mean percentage of low coarse vegetation coverage, followed by Property Values (19.6\%). Lack of coarse vegetation does not, of course, equate with lack of vegetation. These three neighborhood types also contain the highest mean percentage of fine vegetation (mainly grass).

The 2000 lifestyle clusters from PRIZM are also not very good predictors of high coarse or woody vegetation coverage. The model returned an adjusted $R^{2}$ of .041 . Of the 31 PRIZM classes that contained a patch of high coarse vegetation cover, Mid-City Mix had the highest mean percentage (23.6\%), followed by Inner Cities $(22.9 \%)$ and Upstarts \& Seniors (10.9\%). Similar to the 1960 lifestyle clusters, PRIZM classifications are better at predicting a lack of coarse vegetation patches. This model generated an adjusted $R^{2}$ of .297 (sig. .000). PRIZM classes with the highest mean values of low coarse vegetation coverage are Executive Suites (19.6\%), Kids and Cul-de-Sacs (13.8\%), and New Beginnings (12.1\%).

PRIZM classes are, however, much better at predicting high fine vegetation coverage (grass and herbaceous cover). The model generates an adjusted $R^{2}$ of .361 (sig .000). Descriptive statistics show that the highest mean values are for Mid-City Mix (25.5\%), New Empty Nests (21.7\%), and Suburban Sprawl (10.4\%). Lifestyle clusters for 1960 are not as strong in predicting present-day coverage of fine vegetation. That model returned an adjusted $R^{2}$ of .150 (sig. 000), better than for the coarse vegetation model but weaker than the PRIZM classes model.

\section{Discussion}

When it comes to understanding present tree canopy patterns in the Gwynns Falls Watershed, the 1960s matter. Using population and housing characteristics, we find that neighborhoods that had a high percentage of professionals and a low percentage of preWWII houses in 1960 are now the leafiest neighborhoods in the watershed. Neighborhoods that have high median incomes and low population densities in 2000 are also good predictors of high coarse vegetation, but the 1960 characteristics are more significant.

Lifestyle clusters in 1960 are not very good at predicting the amount of coarse vegetation in 2000, but are better at predicting the lack of it. The same holds true for the PRIZM classes for the year 2000. However, PRIZM classifications are very good predictors of fine vegetation coverage (e.g. grass and fine herbaceous cover). 1960 lifestyle clusters are better at predicting fine vegetation than coarse vegetation coverage, but are not as strong as PRIZM classes. Neither the 1960 nor the 2000 demographics are good predictors of high fine vegetation coverage. In summary, 1960 demographics are better predictors of high tree cover, while current lifestyle classes are better predictors of high grass cover in the Gwynns Falls Watershed (Table 4). These results suggest that lawns are better connected to lifestyle than trees, while demographics and housing, especially those from decades ago, are better predictors of trees than grass. 
Table 4 Strength of associations between 1960 and 2000 demographics/housing and lifestyle with patches of high coarse and high fine vegetation in 1999

\begin{tabular}{llll}
\hline & Independent variable group & $\begin{array}{l}\text { High coarse vegetation } \\
\text { cover in 1999 (Trees) }\end{array}$ & $\begin{array}{l}\text { High fine vegetation } \\
\text { cover in 1999 (Grass) }\end{array}$ \\
\hline \multirow{2}{*}{2060} & Demographics/housing & Best & Poor \\
& Lifestyle & Poor & Fair \\
& Demographics/housing & Good & Fair \\
& Lifestyle & Poor & Best \\
\hline
\end{tabular}

The association between demographics, lifestyle clusters, and vegetation patterns is simply that - an association - but it points to social and housing characteristics that should be investigated further. Those in professional occupations in 1960 may have been the individuals who planted and cared for trees, or it could be that professionals were attracted to already leafy districts of the city. Since part of the canopy cover is in parks, it is possible that professionals were attracted to neighborhoods close to parks, or lobbied for their maintenance and care. An analysis of historic landcover patterns may provide clues.

The social and housing legacies on the landscape must also be placed in their appropriate contexts (Conway and Urbani 2007). Timing of growth is important not only for permitting biological growth and senescence of trees or other vegetation, but also corresponds with particular cultural and legal milieus. Post-WWII housing differed markedly from pre-war housing, with a greater emphasis on detached single family homes for a growing middle class, fueled by federal mortgage subsidies and federally funded highways (Hayden 2003). The detached home set in a landscaped garden was not unique to this era, but the scale of development was significantly greater in the 1950s than the 1930s. New building codes that required minimum set-backs from streets, and zoning laws that forbade mixed-use development helped to move Baltimore housing away from its iconic row house neighborhoods to neighborhoods of houses in a sea of green grass.

Place histories matter as well. In the well-treed neighborhood of Mount Royal, for instance, a long history of racial segregation likely contributed to the distribution of trees we see today. Owing to a neighborhood improvement association that actively promoted tree planting and a restrictive covenant that reserved properties within the area for white occupancy only, a disproportionate share of amenities - in this case trees-flowed into Mount Royal while a host of disamenities such as polluting industries and undesirable commercial development was redirected elsewhere (Buckley 2010). Larger socio-spatial trends, such as white and middle-class flight, the tide of suburbanization, and massive economic restructuring from an industrial to a service economy all left their imprint on the social and landscape configurations of the watershed.

Linking social characteristics to vegetation patterns has very practical applications. In 2006, the City of Baltimore declared that it would double its tree canopy cover over the next twenty years. This ambitious goal is one of many efforts across the United States to reestablish trees and parks in cities as natural amenities that provide multiple ecological and social benefits. Baltimore has a long history of street tree planting; it was one of the first cities in the country to establish a City Forestry Division after passing a Tree Ordinance in 1912. Then as now, the municipal administration recognized that trees would beautify the city, clean the air, increase property values, regulate extremes of temperature, and reduce loads on stormwater systems.

What may have been forgotten is that trees in the city were not universally loved and admired. Newspaper accounts from the 1950s and 1960s reveal that some residents, 
especially those living in East Baltimore, were hardly enamored with the idea of having street trees planted in their neighborhoods. As long-time city forester Charles Young lamented in a 1955 interview: "I was under the impression that all people like to have trees planted in front of their houses until I started planting trees in front of houses" (Evening Sun 24 May 1955). Some East Baltimoreans' disdain for trees was carried to an extreme. "I just don't like trees," confessed one resident in 1967. "I don't like greenery. I like clean, uncluttered concrete" (Evening Sun 25 April 1967). More recently in New York City, an initiative to plant one-million trees in the city's boroughs has prompted pockets of resistance. Some residents have protested that street trees will worsen their allergies, drop branches on their cars, or that the roots will penetrate their foundations. A public relations campaign to ease some of those concerns has not convinced all New Yorkers of the values of street trees. That residents are responsible for raking leaves does not help matters (Dominus 2008). These stories suggest that simply planting trees does not mean Baltimore or New York will achieve its goals. Because households are responsible for much of a city's vegetation, the success of such efforts will depend, in part, on understanding the social predictors of vegetation (Yaoqi et al. 2007).

Baltimore's goal of doubling its tree canopy cannot be carried out without trees being planted and cared for on private land in addition to public land (City of Baltimore Recreation and Parks 2007). Annual tree mortality rates in Baltimore are close to 7\%, partly due to neglect, and new young trees are particularly susceptible (Nowak et al. 2004). That being the case, it is imperative to know why trees thrive in some communities and not in others, beyond the physical properties of the sites. Stormwater management, including reduction of impervious surfaces and protection of the Chesapeake from fertilizer runoff, will be most effective if managers understand relationships between social characteristics and vegetation cover (Cadenasso et al. 2007; Pickett et al. 2008). Since the vast majority of land is privately owned, it is the decisions of individuals and households, which often reflect characteristics of neighborhoods, that are crucial to understand. As the 1960s matter for understanding the present distribution of trees in Baltimore, the 2000s will matter for city managers as they attempt to green the city over the next 40 years.

Acknowledgments Research for this article was supported through awards from the National Science Foundation Long-Term Ecological Research program (DEB 0423476), the National Science Foundation Human and Social Dynamics program (SBE-HSD 0624159), and the U.S. Department of Agriculture Forest Service (06JV11242300039). The authors thank the anonymous reviewers for their insightful comments and suggestions.

Open Access This article is distributed under the terms of the Creative Commons Attribution Noncommercial License which permits any noncommercial use, distribution, and reproduction in any medium, provided the original author(s) and source are credited.

\section{Appendix I: Factor loadings for PCA of 1960 population and housing characteristics by census tract}

\section{Blue Blood}

Eigen value: 6.168

Percent of Variance: 12.436

Characteristics: High income census tracts with high value homes. Persons are employed in the professional and managerial classes and have college degrees.

Factor loadings:

[.900] percent of families with annual incomes greater than $\$ 25,000$ 
[.879] percent of all housing units with value of more than $\$ 35 \mathrm{~K}$

[.838] percent of families with annual income less between $\$ 15,000$ and $\$ 25,000$

[.801] percent of all housing units with value of between $\$ 25$ and $35 \mathrm{~K}$

[.819] percent of persons over 25 years of age with 4 years or more of college education

[.608] percent of employed civilians 14 and over, professional, technical, and kindred workers

[.429] percent of employed civilians 14 and over, managers, officials, and proprietors

[-.522] percent of persons over 25 years of age with 8 years or less education

[-.491] percent of employed civilians 14 and over, operatives and kindred workers, including mine

\section{Inner-city Minority}

Eigen value: 6.086

Percent of Variance: 11.270

Characteristics: Low income, nonwhite, young population living in high densities. Persons are employed in the laborer and household services occupations.

Factor loadings:

[.802] percent of population nonwhite

[.801] percent of population between 5 and 19 years

[.763] percent of employed civilians 14 and over, private household workers

[.750] percent of population under 5 years

[.630] percent of employed civilians 14 and over, laborers, except farm and mine

[.564] percent of families with annual income less between $\$ 1,000$ and $\$ 5,000$

[.517] percent of families with annual income less than $\$ 1,000$

[.455] population density, persons per square kilometer

$[-.767]$ percent of population between 20 and 64 years

[-.674] percent of population white

\section{High School Achievers}

Eigen value: 5.881

Percent of Variance: 10.891

Characteristics: High School educated population living in newer, low-density housing and with moderate incomes.

Factor loadings:

[.720] percent of all housing units with value of between $\$ 10$ and $12.5 \mathrm{~K}$

[.688] percent of persons over 25 years of age with 4 years of high school education

[.662] percent of houses moved into between 1954 and 1957

[.513] percent of all housing units with value of between $\$ 12.5$ and $15 \mathrm{~K}$

[.495] percent of families with annual income less than $\$ 1,000$

[.479] percent of houses built between 1950 and 1960

$[-.800]$ percent of all housing units with value of under $\$ 5,000$

$[-.623]$ percent of all housing units with value of between $\$ 5$ and $7.5 \mathrm{~K}$

$[-.553]$ percent of families with annual income less between $\$ 1,000$ and $\$ 5,000$

$[-.543]$ percent of families with annual income less than $\$ 1,000$

$[-.528]$ percent of houses built before 1940

[-.503] percent of employed civilians 14 and over, laborers, except farm and mine

[-.461] population density, persons per square kilometer

[-.432] percent of houses moved into before 1940 


\section{Post-War Dreams}

Eigen Value: 5.599

Percent of Variance: 10.368

Characteristics: White, middle-income populations who own single, detached dwellings. Craftsmen and foremen are the dominant occupation.

Factor loadings:

[.852] percent of households in single unit dwellings

[.817] percent of households in owner-occupied units

[.605] percent of employed civilians 14 and over, craftsmen, foremen, and kindred workers

[.453] percent of families with annual income less between $\$ 5,000$ and $\$ 10,000$

[.420] percent of population white

[.402] percent of households with married couple and children under 18 years

[-.732] percent of households in rented units

[-.592] percent of employed civilians 14 and over, service workers, except household

[-.453] percent of population 65 and older

\section{Everything New}

Eigen Value: 4.268

Percent of Variance: 7.903

Characteristics: Young families with children who have recently moved in to new houses. Factor loadings:

[.905] percent of households with married couple and children under 6 years

[.818] percent of households with married couple and children under 18 years

[.661] percent of houses moved into between 1958 and 1960

[.574] percent of houses moved into between 1954 and 1957

[.567] percent of houses built between 1950 and 1960

[.499] percent of population under 5 years

[.405] percent of households with married couple living in own household

[-.492] percent of houses moved into before 1940

[-.434] percent of houses moved into between 1940 and 1953

[-.429] percent of houses built before 1940

\section{Property Values}

Eigen value: 3.406

Percent of Variance: 6.308

Characteristics: Areas of higher-valued properties.

Factor loadings:

[.743] percent of all housing units with value of between $\$ 17.5$ and $20 \mathrm{~K}$ [.735] percent of all housing units with value of between $\$ 15$ and $17.5 \mathrm{~K}$

[.608] percent of all housing units with value of between $\$ 20$ and $25 \mathrm{~K}$

$[-.618]$ percent of all housing units with value of between $\$ 5$ and $7.5 \mathrm{~K}$

\section{Euro Ghettos}

Eigen value: 2.647

Percent of Variance: 4.902

Characteristics: High percentage of white, foreign persons and of foreign parentage. Dominant occupations in sales.

Factor loadings: 
[.837] percent of population foreign born

[.808] percent of population of foreign or mixed parents

[.619] percent of employed civilians 14 and over, sales workers

[.336] percent of population white

\section{Empty Nesters}

Eigen value: 2.266

Percent of Variance: 4.197

Characteristics: Older, married couples living in older houses.

Factor loadings:

[.692] percent of households with married couple living in own household

[.657] percent of population 65 and older

[.475] percent of houses built before 1940

\section{Farm Country}

Eigen value: 2.210

Percent of Variance: 4.092

Characteristics: Dominated by farmers and farm laborers.

Factor loadings:

[.897] percent of employed civilians 14 and over, farmers and farm managers

[.894] percent of employed civilians 14 and over, farm laborers

\section{References}

Anderson TG (2001) The creation of an ethnic culture complex region: Pennsylvania Germans in Central Ohio, 1790-1850. Hist Geogr 29:135-157

Buckley GL (2010) America's forest legacy: a century of saving trees in the old line state. Center for American Places, Santa Fe (in press)

Burgi MA, Hersperger AM, Schneeberger N (2004) Driving forces of landscape change - current and new directions. Landscape Ecol 19:857-868

Cadenasso ML, Pickett STA, Grove JM (2006) Dimensions of ecosystem complexity: heterogeneity, connectivity, and history. Ecol Complex 3:1-12

Cadenasso ML, Pickett STA, Schwarz K (2007) Spatial heterogeneity in urban ecosystems: reconceptualizing land cover and a framework for classification. Front Ecol Environ 5:80-88

City of Baltimore Recreation and Parks (2007) Tree Baltimore, doubling Baltimore's tree canopy one tree at a time: urban forest management plan. Available online: http://www.ci.baltimore.md.us/government/ recnparks/downloads/TreeBaltimore\%20Urban\%20Forest\%20Management\%20Plan.pdf

Conway TM, Hackworth J (2007) Urban pattern and land cover variation in the greater Toronto area. Canadian Geographer-Geographe Canadien 51:43-57

Conway TM, Urbani L (2007) Variations in municipal urban forestry policies: a case study of Toronto, Canada. Urban Forestry \& Urban Greening 6:181-192

Cosgrove DE (1998) Social formation and symbolic landscape. University of Wisconsin Press, Madison

Côté JE, Levine C (2002) Identity formation, agency, and culture: a social psychological synthesis. Erlbaum, Mahwah

Dominus S (2008) For urban tree planters, concrete is the easy part. New York Times 21 April 2008. Available online: http://www.nytimes.com/2008/04/21/nyregion/21bigcity.html?_r=1

Dow K (2000) Social dimensions of gradients in urban ecosystems. Urban Ecosyst 4:255-275

Emmanuel R (1997) Urban vegetational change as an indicator of demographic trends in cities: the case of Detroit. Environ \& Plann B 24:415-426

Escobedo FJ, Nowak DJ, Wagner JE, Luz De la Maza C, Rodríguez M, Crane DE, Hernández J (2006) The socioeconomics and management of Santiago de Chile's public urban forests. Urban Forestry \& Urban Greening 4:105-114 
Fraser EDG, Kenney WA (2000) Cultural background and landscape history as factors affecting perceptions of the urban forest. J Arboric 26:106-112

Gottdiener M, Hutchinson R (2000) The new urban sociology. McGraw-Hill Higher Education, New York

Grimm NB, Faeth SH, Golubiewski NE, Redman CL, Wu J, Bai X, Briggs JM (2008) Global change and the ecology of cities. Science 5864:756

Grove JM (1996) The relationship between patterns and processes of social stratification and vegetation of an urban-rural watershed. Dissertation, Yale University

Grove JM, Cadenasso ML, Burch WR, Pickett STA, O’Neil-Dunne JPM, Schwarz K, Wilson M, Troy AR, Boone CG (2005) Data and methods comparing social structure and vegetation structure of urban neighborhoods in Baltimore, Maryland. Soc Nat Resour 19:117-136

Grove JM, Troy AR, O’Neil-Dunne JPM, Burch WR, Cadenasso ML, Pickett STA (2006) Characterization of households and its implications for the vegetation of urban ecosystems. Ecosystems 9:578-597

Hayden D (2003) Building suburbia: green fields and urban growth, 1820-2000. Pantheon Books, New York

Heynen NC, Lindsey G (2003) Correlates of urban forest canopy cover: implications for local public works. Public Works Manag Policy 8:33-47

Iverson LR, Cook EA (2000) Urban forest cover of the Chicago region and its relation to household density and income. Urban Ecosyst 4:105-124

Jensen RJ, Gatrell J, Boulton J, Harper B (2004) Using remote sensing and geographic information systems to study urban quality of life and urban forest amenities. Ecol Soc 9:5

Kaplan DH, Wheeler JO, Holloway SR (2004) Urban geography. Wiley, New York

Kirkpatrick JB, Daniels GD, Zagorski T (2007) Explaining variation in front gardens between suburbs of Hobart, Tasmania, Australia. Landsc Urban Plan 79:314-322

Knox PL (1994) Urbanization: an introduction to urban geography. Prentice Hall, Englewood Cliffs

Law NL, Band LE, Grove KM (2004) Nitrogen input from residential lawn care practices in suburban watersheds in Baltimore County, MD. J Environ Plan Manag 47:737-755

Luttik J (2000) The value of trees, water and open space as reflected by house prices in the Netherlands. Landsc Urban Plan 48:161-167

Mansfield C, Pattanayak SK, McDow W, McDonald R, Halpin P (2005) Shades of green: measuring the value of urban forests in the housing market. J Forest Econ 11:177-199

Martin CA, Warren PS, Kinzig AP (2004) Neighborhood socioeconomic status is a useful predictor of perennial landscape vegetation in residential neighborhoods and embedded small parks of Phoenix, AZ. Landsc Urban Plan 69:355-368

Massey DS, Denton NA (1993) American apartheid: segregation and the making of the underclass. Cambridge Harvard University Press, Cambridge

Mennis J (2006) Socioeconomic-vegetation relationships in urban, residential land: the case of Denver, Colorado. Photogramm Eng Remote Sensing 72:911-921

Nowak DJ, Rowntree RA, McPherson EG, Sisinni SM, Kerkmann ER, Stevens JC (1996) Measuring and analyzing urban tree cover. Landscape and Urban Planning 1:49-57

Nowak DJ, Kuroda M, Crane DE (2004) Tree mortality rates and tree population projections in Baltimore, Maryland, USA. Urban Forestry \& Urban Greening 2:139-147

Perkins HA, Heynen N, Wilson J (2004) Inequitable access to urban reforestation: the impact of urban political economy on housing tenure and urban forests. Cities 21:291-299

Pickett STA, Cadenasso ML, Grove JM, Groffman PM, Band LE, Boone CG, Burch WR, Grimmond CSB, Hom J, Jenkins JC, Law NL, Nilon CH, Pouyat RV, Szlavecz K, Warren PS, Wilson MA (2008) Beyond urban legends: an emerging framework of urban ecology, as illustrated by the Baltimore ecosystem study. Bioscience 58:139-150

Ridd MK (1995) Exploring a V-I-S (vegetation-impervious-surface-soil) model for urban ecosystem analysis through remote sensing: comparative anatomy for cities. Int J Remote Sens 16:2165-2185

Robbins P (2007) Lawn people: how grasses, weeds, and chemicals make us who we are. Temple University Press, Philadelphia

Sauer CO (1925) The morphology of landscape. Univ Calif Publ Geogr 2:19-54

Short JR (1996) The urban order. Blackwell, Cambridge

Spirn AW (1984) The granite garden: urban nature and human design. Basic Books, New York

Talarchek GM (1990) The urban forest of New Orleans - an exploratory analysis of relationships. Urban Geogr 11:65-86

Timms D (1971) The urban mosaic: towards a theory of residential differentiation. Cambridge University Press, Cambridge

Troy AR, Grove JM, O’Neil-Dunne JPM, Pickett STA, Cadenasso ML (2007) Predicting opportunities for greening and patterns of vegetation on private urban lands. Environ Manage 40:394-412 
Weiss MJ (2000) The clustered world: how we live, what we buy, and what it all means about who we are. Little, Brown and Company, New York

Yaoqi Z, Hussain A, Deng J, Letson N (2007) Public attitudes toward urban trees and supporting urban tree programs. Environ Behav 39:797-814

Zmyslony J, Gagnon D (2000) Path analysis of spatial predictors of front-yard landscape in an anthropogenic environment. Landscape Ecol 15:357-371

\section{Note}

*PRIZM is a registered product of Claritas Incorporated. 